\title{
SALUD
}

\section{Condiciones higiénicas sanitarias en servicios de alimentación de la V Región Sanitaria de Caaguazú con la aplicación de las 5 claves de la OMS Caaguazú, Paraguay. Años 2016-2017}

\author{
Ninfa Fernández, María Stella Cabral de Bejarano', Gladys \\ Estigarribia ${ }^{1}$, Analía Ortiz ${ }^{1}$, Patricia Ríos ${ }^{1}$
}

\begin{abstract}
Resumen
Introducción: En Paraguay, se dispone de escasa información sobre cómo se organizan y controlan las condiciones higiénico sanitarias de servicios de alimentación de hospitales públicos y privados. Diferentes problemas de carácter estructural y funcional han sido identificados desde diversas instancias en los servicios de alimentación de establecimientos de salud públicos y privados.

Los servicios de alimentación y nutrición de los hospitales tienen como misión dar respuesta a la necesidad de alimentación de los usuarios con alimentos en óptimas condiciones higiénicas y organolépticas en los tiempos establecidos.

Objetivo General: Evaluar las condiciones higiénico-sanitarias de los comedores de hospitales, la portación de patógenos bacterianos y virales y factores de riesgo para aparición de brotes y casos de enfermedades transmitidas por alimentos (ETA) en manipuladores de alimentos, vinculados a variables sociodemográficas en la V Región Sanitaria, Caaguazú (2016- 2017).
\end{abstract}

Material y Método: Se realizó un estudio observacional, descriptivo, de corte transversal, realizado en el año 2017. Se realizó un censo de todos los establecimientos de salud del departamento e ingresaron al estudio 12 establecimientos que contaban con servicios de alimentación y 26 manipuladoras de alimentos. Se aplicó 3 cuestionarios de Buenas Prácticas de Manufactura con relación a las 5 claves de la OMS. Los datos compilados en los cuestionarios se cuantificaron en las planillas Microsoft Excel y analizados con Epi info, versión 7 (CDC, 2001).

Resultados: El 66,7\% de manipuladores de alimentos reportó lavado de manos con la frecuencia recomendada, en el $41 \%$ de los casos los basureros estaban sucios (clave 1). $75 \%$ de manipuladores utilizan diferentes utensilios para tratar alimentos crudos y cocinados, 58,3\% aplicaba métodos apropiados en la degustación (Clave 2). Solo el 16,7 \% mantiene registros de temperatura interna

\footnotetext{
1. Universidad Nacional de Caaguazú. Instituto Regional de Investigación en Salud.

Proyecto de Investigación financiado por el Consejo Nacional de Ciencias y Tecnología.

E-mail: analia.ortizrolon@gmail.com

DOI: $10.26885 /$ rcei.foro.2018.140
} 
de los alimentos (Clave 3). Para alimentos con aliños se limita la exposición a temperaturas elevadas, (Clave 4). Se utiliza el sistema FIFO en $66,7 \%$ de casos para rotación de alimentos, $25 \%$ de manipuladores lava frutas y verduras según indicaciones de inocuidad (Clave 5).

Conclusiones: Los hallazgos muestran deficiencias higiénicas sanitarias en los servicios de alimentación, atribuido a escasa formación en BPM de manipuladores, procesos de capacitación discontinuos y ausencia de normas, requeridas con urgencia para mejorar la higiene de los servicios y proteger la salud de los usuarios.

Palabras clave: hospitales, servicios de alimentación, higiene.

\section{Referencias}

FAO/OMS.(2011). Códex Alimentarius. Manual para los fines del Codex Alimentarius. Roma.

García, L .M. (2014). Buenas prácticas de manufactura en comedores del mercado central de abasto de Asunción, Paraguay. Mem. Inst. Investig. Cienc. Salud, 15(1), p. 42-47.

Naciones Unidas. (1948). Declaracion Universal de los Derechos Humanos.

OPS/OMS. (sf). Nota descriptiva sobre Inocuidad de los alimentos. Recuperado de http://www.who.int/mediacentre/factsheets/fs399/es/

Weiler, N. (2011). Brote de intoxicación alimentaria asociado al consumo de leche ultrapasteurizada en la República del Paraguay. San Lorenzo: Laboratorio Central de Salud Pública. 